\section{Influence of different body mass index cut-off values in assessing the nutritional status of adolescents in a household survey}

\author{
Influência de distintos valores críticos do índice de \\ massa corporal na avaliação do estado nutricional \\ de adolescentes em inquérito domiciliar
}

\author{
1 Escola Nacional de Ciências \\ Estatísticas, Instituto \\ Brasileiro de Geografia e \\ Estatística, Rio de Janeiro \\ Brasil. \\ 2 Coordenação de Prevenção $e$ \\ Vigilância, Instituto Nacional \\ de Câncer, Rio de Janeiro, \\ Brasil. \\ 3 Departamento de Nutrição \\ Social, Universidade Federal \\ Fluminense, Rio de Janeiro, \\ Brasil. \\ 4 Escola Nacional de Saúde \\ Pública Sergio Arouca \\ Fundação Oswaldo Cruz, \\ Rio de Janeiro, Brasil. \\ Correspondence \\ F. S. Gomes \\ Escola Nacional de Ciências \\ Estatísticas, Instituto \\ Brasileiro de Geografia e \\ Estatística. \\ C. P. 7107, Rio de Janeiro, $R J$ \\ 20230-972, Brasil. \\ fabiodasilvagomes@gmail.com
}

\section{Abstract}

The purpose of this study was to evaluate the anthropometric nutritional status of the adolescent population of Niterói, Rio de Janeiro State, Brazil, and the influence of changes in the adopted body mass index (BMI) cut-offs in the nutritional status assessment of the adolescent population. A population-based survey conducted in 2003 obtained data from a probabilistic sample of 1,734 households and 523 adolescents. The multiple proportions test and prevalence ratios were used to analyze differences between estimates obtained from different BMI cut-offs. Changes in cut-off values from the old to the new recommendation of the World Health Organization (WHO) resulted in a significant increase in overweight prevalence among total, male and female adolescent population (25\%, $27 \%$ and $23 \%$, respectively) $(p<0.05)$. There were significant increases in the prevalence of low-BMI-for-age among the total (29\% increase) and male (39\%) adolescent populations when the proposal of the International Obesity Task Force was compared to current WHO BMI-for-age cut-offs ( $p<0.05)$. It is shown that a simple change in cut-off values used to define the anthropometric nutritional status can significantly modify the nutritional profile of an adolescent population.

Adolescent; Nutritional Status; Nutrition Assessment; Anthropometry
Fabio da Silva Gomes 1,2

Luiz Antonio dos Anjos 3,4

Mauricio Teixeira Leite de Vasconcellos 1

\section{Introduction}

The rising prevalence of obesity in children and adolescents is already recognized as a serious public health problem in many parts of the world 1,2. Wang et al. 3 have documented an increase in the prevalence of overweight among Brazilian youths (6-18years old) from 4.1 to $13.9 \%$, between 1975 and 1997, from 6.4 to $7.7 \%$ in China (between 1992 and 1998), and from 15.4 to $25.6 \%$ in the USA (between 1971-1974 and 1988-1994) associated with a decrease in the prevalence of underweight in these countries: 14.8 to $8.6 \%$ in Brazil, 14.5 to $13.1 \%$ in China, and 5.1 to $3.3 \%$ in the USA.

Data from regional and national surveys in Brazil have shown a decrease in underweight 4,5 , a reduction of 6.5 percentage points and a worrying increase in overweight/obesity (from 3.7 to $12.6 \%$ ) among adolescents in the last few decades 3 . The interest in assessing adolescents is relatively recent and there is a series of classifications used to define the nutritional status of individuals or the population. Thus, the results and interpretations of the studies may differ depending on the methodological strategy adopted 1,6,7. The demand for a global approach to assess adolescents has prompted the World Health Organization (WHO) to define criteria to be used internationally 8 . The consensus was to use cutoff points of body mass index (BMI = body mass / stature 2 ) for age derived from a re-analysis of the 
1977 National Center for Health Statistics (NCHS) growth curves ${ }^{9}$. The purpose of the present study was to evaluate the influence of using different cut-off points of BMI for age 1,6,8,10 in the assessment of the anthropometric nutritional status of the adolescent population of Niterói, Rio de Janeiro State, Brazil.

\section{Methods}

The data in the present analysis come from the Nutrition, Physical Activity and Health Survey (PNAFS), a household survey conducted in the city of Niterói, from January to December 2003. The city is located in the metropolitan region of Rio de Janeiro and according to the last Brazilian census, in 2000, there were 459,451 inhabitants 11 .

The data were collected following a two-stage probabilistic sample of households. In the first stage, 110 census enumeration areas (CEA) from Niterói were systematically selected, with probability proportional to the number of permanent private households observed in the 2000 population census 11. Prior to selection, the CEAs were ordered from lowest to highest according to the head-of-household's mean nominal monthly income, thus implicitly stratifying the CEAs by mean income and ensuring the selection of CEAs from all income levels.

In the second stage, 16 households were selected in each CEA with equal probability, using an inverse sampling procedure 12 analogous to that applied to the World Health Survey in Brazil 13 as described in Bossan et al. 14. All adolescents ( $10 \leq$ age $<20$ years old) that belonged to the selected households were surveyed, leading to a sample size of 1,734 households with 523 adolescents, after exclusions, refusals and losses, as described below.

Sample weights were calculated as the inverse of the product of selection probabilities in each stage 12,13 and then calibrated to ensure consistency of the estimates with known population totals for post-strata, comprised of gender and age brackets 15 .

On a previously scheduled day, the head of household signed a free informed consent form, then answered a questionnaire about family and individual information 14. For each adolescent, body mass $(\mathrm{kg})$, stature $(\mathrm{cm})$, physiological condition (if pregnant or nursing), and basic demographic data were obtained.

Body mass was measured once and stature was measured twice using standard procedures described elsewhere 14. Data from one pregnant and one nursing adolescent, and two adolescents with missing limbs or limbs in casts were exclud- ed from the analysis; 27 adolescents refused to be measured and 32 additional adolescents were unavailable to be measured even after three attempts.

BMI was calculated as body mass (kg) divided by stature (mean of the two measurements) squared $\left(\mathrm{m}^{2}\right)$. BMI for age and sex was used to determine the adolescents' nutritional status (i.e. underweight/thinness, adequate, overweight and obesity) according to three classification methods: the one recommended by the World Health Organization in 1995 (WHO-1995) 6,16; the current method recommended by WHO-2007 8; and the International Obesity Task Force (IOTF) proposal 1,10. In the 1995 classification, despite the suggestion of using the triceps and subscapular skinfold thicknesses along with BMI for the definition of obesity, the publication indicated that BMI could be used alone to monitor excess body mass for nutritional surveillance purpose 6 . In fact, the recommendations were based on the BMI distribution values published by Must et al. 16 who recognized the value of using BMI because of: (1) the ease of calculating BMI; (2) the opportunity to work with self-reported information; (3) the adoption of BMI by several consensus; (4) the limitations of and difficulty in obtaining the skinfold thickness measurements. Furthermore, the WHO has recently proposed the use of BMI alone to assess the nutritional status of adolescents. Thus the $95^{\text {th }}$ percentile of BMI of the population adopted as a reference by WHO in 1995 6,16 was used as one of the criteria to define obesity.

Descriptive analyses were carried out for continuous variables (i.e. age, body mass, stature, $\mathrm{BMI}$ ) including minimum and maximum values, estimates of means and its respective standard errors (SE) and 95\% confidence intervals (95\%CI). For these variables, the differences between sexes were analyzed using the Wald test. BMI was categorized according to the three methods cited above (WHO-1995; WHO-2007; IOTF) to estimate the nutritional status. For thinness/low-BMI-forage classification according to Cole et al. 10 , grade 2 was used (the closest to the $-2 \mathrm{Z}$ scores actually recommended by WHO ${ }^{8}$ ).

A comparison test for multiple proportions was conducted to evaluate if the prevalence of each nutritional status category differed significantly between distinct proposals of BMI-for-age cut-off points. The test consists of the estimation of 95\%CI for differences among all possible pairs of prevalences at the same nutritional status category.

Prevalence ratios (PR), and its respective $95 \% \mathrm{CI}$, were estimated to identify the magnitude of proportional differences between prevalence estimates of each nutritional status category 
according to the three different proposals. The Taylor linearization method 17 was used to estimate variances needed to build 95\%CI for PR. The WHO-2007 criterion was set as the basis of comparison.

For all test statistics a 5\% significance level was used. 95\%CI of prevalences were built using a multivariate procedure, adjusting alpha to the number of regions (parts) in which a total number of individuals was divided according to nutritional status categories. In order to guarantee that confidence intervals of the prevalence of each category are included in a $95 \%$ level of confidence simultaneously (e.g. if the sum of four prevalence is equal to $100 \%$, to guarantee simultaneously a $95 \%$ significance level, it is necessary to use an alpha equal to $0,05 / 4$ ). All estimates and statistical tests were based on structural information of the sampling design and calibrated weights, by using the survey library developed in R. Calibration residuals were also considered in the estimation of variance and derived statistics and tests. All analyses were conducted in $\mathrm{R}$ language using version 2.6.0 (The R Foundation for Statistical Computing, Vienna, Austria; http://www.r-project.org). The Institutional Review Board of the Sergio Arouca National School of Public Health, Oswaldo Cruz Foundation approved all the research procedures.

\section{Results}

Body mass and stature means (95\%CI) were significantly higher in males in comparison to females: $55.5 \mathrm{~kg}(53.2-57.7)$ versus $50.8 \mathrm{~kg}$ (49.2$52.3)$, and $164.7 \mathrm{~cm}$ (162.7-166.8) versus $156.8 \mathrm{~cm}$ (155.7-157.8), respectively. However, mean BMI did not differ between sexes $(\mathrm{p}=0.22)$ (Table 1$)$.

The prevalence of overweight in males estimated by the current WHO recommendation (WHO-2007) 8 was significantly higher than the old WHO recommendation estimates (WHO1995) 6,16 , but it was not significantly different from the estimates using IOTF's 1,10. For female adolescents and for adolescents from both sexes, the same pattern was found, except that WHO2007 estimates were also significantly higher than the IOTF's estimates (Table 2).

The prevalence estimates of obesity using all three procedures (WHO-1995; WHO-2007; IOTF) were not different in both male and female adolescent populations. For the total (male + female) adolescent population, WHO-2007 and WHO-1995 estimates differed significantly from IOTF's estimates but did not differ from each other (Table 2).

Low-BMI-for-age/thinness prevalences for male and total adolescent population according to WHO-1995 cut-off points were the highest estimates followed by the WHO-2007 and IOTF estimates, consecutively, and all significantly different. Prevalences of low-BMI-for-age/thinness in girls were not significantly different (Table 2).

Changing the cut-off values used to determine the nutritional status of adolescents from the older WHO-1995 to the new WHO-2007 recom-

Means, $95 \%$ confidence intervals $(95 \% \mathrm{Cl})$, standard error (SE) estimates, and minimum and maximum values for body measurements and ages of female and male populations ( $\geq 10$ and $<20$ years) in Niterói, Rio de Janeiro State, Brazil, 2003 *

\begin{tabular}{|c|c|c|c|c|c|}
\hline & Mean & $95 \% \mathrm{Cl}$ & SE & Minimum & Maximum \\
\hline \multicolumn{6}{|l|}{ Male } \\
\hline Age (years) & 15.1 & $14.7-15.5$ & 0.2 & 10.0 & 19.9 \\
\hline Body mass (kg) & 55.5 & $53.2-57.7$ & 1.2 & 25.8 & 109.1 \\
\hline Stature $(\mathrm{cm})$ & 164.7 & $162.7-166.8$ & 1.0 & 132.8 & 188.8 \\
\hline BMI $\left(\mathrm{kg} / \mathrm{m}^{2}\right)$ & 20.0 & $19.5-20.6$ & 0.3 & 14.0 & 37.1 \\
\hline \multicolumn{6}{|l|}{ Female } \\
\hline Age (years) & 15.0 & $14.6-15.4$ & 0.2 & 10.0 & 19.9 \\
\hline Body mass $(\mathrm{kg})$ & 50.8 & $49.2-52.3$ & 0.79 & 23.3 & 105.9 \\
\hline Stature $(\mathrm{cm})$ & 156.8 & $155.7-157.8$ & 0.55 & 129.0 & 176.5 \\
\hline BMI $\left(\mathrm{kg} / \mathrm{m}^{2}\right)$ & 20.4 & $19.9-20.9$ & 0.3 & 13.0 & 37.2 \\
\hline
\end{tabular}

* Body mass and stature differed significantly between sexes $(p<0.001)$, but age $(p=0.63)$ and BMI $(p=0.22)$ did not. 
Nutritional status according to different cut-off point proposals and sex of adolescents from Niterói, Rio de Janeiro State, Brazil, 2003.

\begin{tabular}{|c|c|c|c|c|c|c|c|c|c|c|c|c|}
\hline \multirow[t]{2}{*}{ Nutritional status } & \multicolumn{2}{|c|}{$\begin{array}{l}\text { IOTF } 1,10 \\
{[\mathrm{~A}]}\end{array}$} & \multicolumn{2}{|c|}{$\begin{array}{l}\text { WHO-1995 6,16 } \\
{[B]}\end{array}$} & \multicolumn{2}{|c|}{$\begin{array}{c}\text { WHO-2007 } 8 \\
{[C]}\end{array}$} & \multirow[t]{2}{*}{$|A-B|$} & \multirow[t]{2}{*}{$95 \% \mathrm{Cl}$} & \multirow[t]{2}{*}{$|B-C|$} & \multirow[t]{2}{*}{$95 \% \mathrm{Cl}$} & \multirow[t]{2}{*}{$|\mathrm{A}-\mathrm{C}|$} & \multirow[t]{2}{*}{$95 \% \mathrm{Cl}$} \\
\hline & $\%$ & $95 \% \mathrm{Cl}$ & $\%$ & $95 \% \mathrm{Cl}$ & $\%$ & $95 \% \mathrm{Cl}$ & & & & & & \\
\hline \multicolumn{13}{|l|}{ Total } \\
\hline Low-BMI-for-age/thinness & 2.7 & $0.0-5.6$ & 6.3 & $1.8-10.8$ & 3.9 & $0.0-7.8$ & 3.6 & $1.4-5.7$ * & 2.4 & $0.8-4.1$ * & 1.2 & $0.1-2.1$ * \\
\hline Adequate & 81.0 & $77.2-84.9$ & 78.4 & $72.9-83.8$ & 77.4 & 71.9-82.8 & 2.6 & $0.1-5.2$ * & 1.0 & $0.0-3.5$ & 3.6 & $1.9-5.5$ * \\
\hline Overweight & 12.1 & $9.0-15.2$ & 10.2 & $6.7-13.8$ & 13.6 & $9.6-17.5$ & 1.9 & $0.2-3.6$ * & 3.4 & $1.6-5.1 *$ & 1.5 & $0.0-2.9$ \\
\hline Obesity & 4.1 & $2.2-6.1$ & 5.1 & $2.5-7.7$ & 5.2 & $2.6-7.8$ & 1.0 & $0.1-1.9$ * & 0.1 & $0.0-0.3$ & 1.1 & $0.2-2.0$ * \\
\hline \multicolumn{13}{|l|}{ Male } \\
\hline Low-BMI-for-age/thinness & 2.7 & $0.0-6.1$ & 8.8 & $2.7-14.9$ & 4.5 & $0.2-8.8$ & 6.1 & $2.3-9.9 *$ & 4.3 & $1.1-7.5$ * & 1.8 & $0.0-3.5$ \\
\hline Adequate & 82.5 & $76.0-89.1$ & 76.6 & $69.0-84.2$ & 77.4 & $69.8-85.0$ & 5.9 & $1.7-10.1$ * & 0.8 & $0.0-3.5$ & 5.1 & $2.0-8.2$ * \\
\hline Overweight & 10.3 & $5.1-15.5$ & 8.8 & $4.0-13.6$ & 12.1 & $6.7-17.6$ & 1.5 & $0.0-4.3$ & 3.3 & $0.7-5.9$ * & 1.8 & $0.0-4.8$ \\
\hline Obesity & 4.4 & 0.9-7.9 & 5.8 & $1.9-9.7$ & 6.0 & 2.1-9.9 & 1.4 & $0.0-3.0$ & 0.2 & $0.0-0.6$ & 1.6 & $0.0-3.2$ \\
\hline \multicolumn{13}{|l|}{ Female } \\
\hline Low-BMI-for-age/thinness & 2.7 & $0.0-7.5$ & 3.8 & $0.0-8.7$ & 3.2 & $0.0-8.1$ & 1.1 & $0.0-2.4$ & 0.6 & $0.0-1.4$ & 0.5 & $0.0-1.5$ \\
\hline Adequate & 79.6 & $72.8-86.3$ & 80.1 & $72.8-87.5$ & 77.3 & $70.0-84.6$ & 0.5 & $0.0-1.8$ & 2.8 & $0.2-5.5$ * & 2.3 & $0.4-4.1$ * \\
\hline Overweight & 13.9 & 8.4-19.4 & 11.6 & $6.3-16.9$ & 15.0 & $9.6-20.5$ & 2.3 & $0.3-4.3$ * & 3.4 & $0.9-5.9$ * & 1.1 & $0.0-2.9$ \\
\hline Obesity & 3.8 & $0.8-6.8$ & 4.4 & $1.3-7.5$ & 4.4 & $1.3-7.5$ & 0.6 & $0.0-1.4$ & 0.0 & - & 0.6 & $0.0-1.4$ \\
\hline
\end{tabular}

* Indicates that absolute differences between estimates are significantly different from zero at $95 \%$ confidence level (95\% Cl).

mendation resulted in significant $25 \%, 27 \%$ and $23 \%$ increases in overweight prevalence among total, male and female adolescent populations respectively (Table 3 ). There were significant increases $(29 \%$ and $39 \%)$ in the prevalence of lowBMI-for-age among total and male adolescent populations, respectively, when IOTF's proposal was adopted instead of the WHO-2007 (Table 3).

\section{Discussion}

The limitations of BMI-for-age to define the nutritional status of adolescents have been widely described and consist of: (1) lower sensitivity to assess body composition in comparison to other measures such as skinfold thickness; (2) the imposition of age brackets that do not necessarily reflect the adolescent's physiological stage (developmental and maturational stages); and (3) not being able to identify central adiposity 18 .

Despite these limitations, in the past few years there have been a number of ethnic-specific, regional, national and international suggestions of BMI-for-age cut-off values to define the nutritional status of adolescents 1,8,10,19,20,21,22,23,24 which makes comparisons between studies difficult. The present study has documented the problems of comparing the results of studies assessing the nutritional status of adolescents when distinct proposals for cut-off values are used. It is possible to illustrate this problem by comparing the prevalence of overweight in female adolescents of Niterói, from the present study, with the results of a study in schoolchildren from the city of Rio de Janeiro 5 , both samples from the Metropolitan area of Rio de Janeiro. Based on the criteria proposed by the IOTF 1 the estimates of the two studies are $13.9 \%$ and $17.7 \%$, respectively.

If the estimates for the Niterói population had been obtained according to the WHO-1995 cut-off points there would have been a significant increase in the difference in comparison to the estimates for schoolchildren from Rio de Janeiro using the IOTF cut-off points (from 3.8 to 6.1 between studies). This represents a $59.5 \%$ increase in estimates, simply because it was not observed that the studies used different criteria.

It is also common to find comparisons of nutritional status in the literature that ignore distinct age brackets used to define adolescence. Many studies, out of convenience or sampling strategies, do not include all individuals from the 10-20 age range 6,8. For example, Anjos et al. 5 used a sample of 10 to 18-year-old schoolchildren from public schools in Rio de Janeiro. Vieira et al. 25 (p. 2998) concluded that "the IOTF classification is accurate for assessing overweight, but it underestimates the proportion of obese adolescents" by analyzing data from 10-12 years old adolescents 
Prevalence ratios (PR) and its 95\% confidence intervals (95\% Cl) for adolescents from Niterói, Rio de Janeiro State, Brazil (2003) by selected cut-off values for classification of anthropometric nutritional status (setting WHO-2007 as the common denominator for all PR), by nutritional status and sex.

\begin{tabular}{|c|c|c|c|c|c|}
\hline \multirow[t]{2}{*}{ Nutritional status } & \multicolumn{2}{|c|}{ IOTF 1,10 } & \multicolumn{2}{|c|}{ WHO-1995 6,16 } & \multirow{2}{*}{$\begin{array}{c}\text { WHO-2007 } 8 \\
\text { PR }\end{array}$} \\
\hline & PR & $95 \% \mathrm{Cl}$ & PR & $95 \% \mathrm{Cl}$ & \\
\hline \multicolumn{6}{|l|}{ Total } \\
\hline Low-BMI-for-age/thinness & 0.71 & $0.43-0.99$ * & 1.63 & $0.99-2.26$ & 1 \\
\hline Adequate & 1.05 & $1.02-1.07$ * & 1.01 & $0.98-1.05$ & 1 \\
\hline Overweight & 0.89 & $0.79-1.00$ & 0.75 & $0.64-0.87$ * & 1 \\
\hline Obesity & 0.79 & $0.62-0.96$ * & 0.98 & $0.94-1.02$ & 1 \\
\hline \multicolumn{6}{|l|}{ Male } \\
\hline Low-BMI-for-age/thinness & 0.61 & $0.31-0.91 *$ & 1.96 & $1.00-2.92$ & 1 \\
\hline Adequate & 1.07 & $1.02-1.11$ & 0.99 & $0.93-1.04$ & 1 \\
\hline Overweight & 0.85 & $0.62-1.08$ & 0.73 & $0.54-0.92$ * & 1 \\
\hline Obesity & 0.74 & $0.49-0.99$ * & 0.96 & $0.89-1.04$ & 1 \\
\hline \multicolumn{6}{|l|}{ Female } \\
\hline Low-BMI-for-age/thinness & 0.84 & $0.51-1.17$ & 1.17 & $0.83-1.51$ & 1 \\
\hline Adequate & 1.03 & $1.00-1.05$ & 1.04 & $1.00-1.07$ & 1 \\
\hline Overweight & 0.92 & $0.81-1.04$ & 0.77 & $0.62-0.93$ * & 1 \\
\hline Obesity & 0.86 & $0.68-1.04$ & 1.00 & $1.00-1.00$ & 1 \\
\hline
\end{tabular}

* PR significantly different from 1.

only. Moreover, the authors have compared their prevalence, sensitivity and specificity estimates with other results derived from a study that have analyzed 12-18 years old adolescents 26 . Von Der Heyde et al. 27 have evaluated individuals aged 12-18 to assess the nutritional status of the "adolescent population” of Curitiba, Paraná, Brazil. In fact, when the purpose is to assess adolescents' nutritional status, individuals aged between 10 and 18 , or 12 and 18 , are considered adolescents. However, estimates for these groups, cannot be considered estimates for an adolescent population but for an adolescent population for a given age bracket, and the nutritional status assessed by anthropometry may vary significantly.

To illustrate this problem, estimates obtained in the present study were restricted to adolescents aged 10-18 and compared with the results of schoolchildren from Rio de Janeiro ${ }^{5}$ using the same classification method (WHO-1995) 6,16. This comparison indicates a $11.1 \%$ and $15.5 \%$ prevalence of overweight among male adolescents from Niterói and Rio de Janeiro public schools 5 , respectively; a 4.4 percentage points difference. Ignoring differences in age brackets that define an "adolescent population" (10-18 years in Rio de Janeiro and 10-19.9 years in Niterói) the prevalence estimates of overweight in male adolescents in Niterói is $8.8 \%$. Hence, there is a $52.3 \%$ increase in difference between male adolescent estimates from the two studies, from 4.4 percentage points to 6.7 .

Jinabhai et al. ${ }^{28}$ compared the prevalences of overweight and obesity in South African Black school-goers aged 13-17.9 years according to IOTF's BMI-for-age cut-off values ${ }^{1}$ with other studies from several countries that had used the same criteria. However, different age brackets were used in the studies, and most of them mixed children and adolescents in one age bracket. Abalkhail 29 concluded that increase in overweight and obesity prevalences among Saudi students coincide with increases documented in the USA and Western European countries but different classification methods and age brackets were used in the studies. A study by Serra Majem et al. 30 compared obesity prevalences among European children and adolescents based on studies that used different age brackets, BMI-for-age cut-off values, and even different anthropometric and body composition indexes. The results of the present study indicate that such comparisons should be made with extreme caution.

Despite the validation of BMI-for-age as an index for predicting overweight/obesity and underweight in adolescents 31 and its correlations with body fatness 32 , risk indicators for cardiovascular diseases 33 , dyslipidemias 34 , and mortality in the long-term 35 it is important to notice that when it comes to classification methods, those 
correlations may vary according to the cut-off values adopted. Mei et al. 31 have validated the use of BMI-for-age to predict overweight and underweight using the age- and sex-specific BMI reference developed by the Centers for Disease Control and Prevention (CDC) 7 . However, it is important to stress that it was validated using CDC's reference, and this conclusion could change if the nutritional status of the adolescents had been defined by the WHO-2007 classification instead of CDC's 7 .

Additionally, although validation is essential, now that there is a definition of an international recommendation to assess nutritional status in adolescents (with inherent method limitations) what is really important is that national and regional estimates use a common method to allow comparisons within and between countries. Even if a country has developed its own reference, and even if it were more adequate to follow its adolescent population, it would be very helpful to present estimates according to an internationally recommended method, which would allow the identification of moves in the gaps between and within countries and continents 1,6,25.

Along these lines, it is necessary to keep investing in the identification of cut-off values that are able to predict adolescence and adulthood health status, body fatness, and risk for noncommunicable diseases. So far, the cut-off values have been defined essentially based on population distributions 16 or by projecting values to adulthood 1,10 without necessarily establishing a relationship with health outcomes. There are, however, a few studies in this direction. For example, Sardinha et al. 36 have estimated BMI values that correspond to the $25 \%$ (boys) and $30 \%$ (girls) body fat percentage cut-off values proposed by Williams et al. 37 for boys and girls based on risk factors for cardiovascular diseases and dyslipidemia. The BMI values varied from 20 to $24 \mathrm{~kg} / \mathrm{m}^{2}$ depending on age and sex. These values are closer to overweight rather than the three BMI-for-age cut-off values used in the present study to identify obesity (WHO-1995; WHO2007; IOTF).

The comparison between the WHO-1995 6,16, IOTF 1,10 and WHO-2007 8 classification methods have documented that a simple change in cut-off values used to define the anthropometric nutritional status of adolescents can significantly modify the nutritional profile of an adolescent population. The updated BMI-for-age cut-off values recently recommended by WHO has resulted in significant increases in the prevalence of overweight among total, male and female adolescent populations (25, 27 and $23 \%$, respectively) of Niterói. On the other hand, despite the absence of significance in this study, it is expected that relevant reductions in the prevalence of low-BMI-for-age may occur. This is critical when comparing changes across time to avoid attributing reductions to interventions or public policies when in fact it could just be due to a change in methods. Until there is a uniform internationally-agreed consensus, it would be helpful if studies presented estimates using several cut-off values, allowing comparisons with older studies so that disparities between and within countries and between different points in time could be properly assessed.

\section{Resumo}

Este artigo tem por objetivo avaliar o estado nutricional antropométrico da população adolescente residente em Niterói, Rio de Janeiro, Brasil, bem como a influência das mudanças nos valores críticos de índice de massa corporal (IMC) na avaliação do estado nutricional dessa população. Uma pesquisa amostral probabilística de base populacional conduzida em 2003 obteve dados de 1.734 domicílios e 523 adolescentes. Testes para múltiplas proporções e razões de prevalência foram utilizados para analisar as diferenças entre estimativas obtidas segundo distintos valores críticos de IMC. Mudanças nos pontos de corte da antiga para a atual recomendação da Organização Mundial da Saúde (OMS) resultaram em aumentos significativos nas prevalências de sobrepeso entre o total de adolescentes, meninos e meninas (25\%, 27\% e 23\%, respectivamente $(p<0,05)$. A proposta da International Obesity Task Force resultou em uma redução significativa de $29 \%$ e $39 \%$ na prevalência de baixo-IMC-para-idade entre o total de adolescentes e meninos, respectivamente, quando comparada à recomendação atual da OMS ( $p<0,05)$. Foi evidenciado que uma simples mudança nos valores de corte empregados na definição do estado nutricional pode alterar significativamente o perfil nutricional de uma população adolescente.

Adolescente; Estado Nutricional; Avaliação Nutricional; Antropometria 


\section{Contributors}

L. A. Anjos and M. T. L. Vasconcellos planned the research. M. T. L. Vasconcellos designed the sample. F. S. Gomes and M. T. L. Vasconcellos calculated the natural and calibrated sampling weights and performed the statistical analyses. F. S. Gomes wrote the first draft of the paper, which was revised and approved by the other authors.

\section{References}

1. Cole TJ, Bellizzi MC, Flegal KM, Dietz WH. Establishing a standard definition for child overweight and obesity worldwide: international survey. BMJ 2000; 320:1240-3.

2. World Health Organization. Obesity: preventing and managing the global epidemic. Report of a WHO Consultation on Obesity. Geneva: World Health Organization; 1998.

3. Wang Y, Monteiro CA, Popkin BM. Trends of obesity and underweight in older children and adolescents in the United States, Brazil, China, and Russia. Am J Clin Nutr 2002; 75:971-7.

4. Monteiro CA, Conde WL, Popkin BM. A tendência secular da obesidade segundo estratos sociais: Nordeste e Sudeste do Brasil, 1975-1989-1997. Arq Bras Endocrinol Metabol 1999; 43:186-94.

5. Anjos LA, Castro IRR, Engstrom EM, Azevedo AMF. Crescimento e estado nutricional em amostra probabilística de escolares no Município do Rio de Janeiro, 1999. Cad Saúde Pública 2003; 19 Suppl 1: S171-9.

6. World Health Organization. Physical status: the use and interpretation of anthropometry. Report of a WHO Expert Committee. Geneva: World Health Organization; 1995. (Technical Report Series, 854).

7. Kuczmarski RJ, Ogden CL, Guo SS, GrummerStrawn LM, Flegal KM, Mei Z, et al. 2000 CDC Growth Charts for the United States: methods and development. Vital Health Stat 11 2002; (246):1190.

8. De Onis M, Onyango AW, Borghi E, Siyam A, Nishida C, Siekmanna J. Development of a WHO growth reference for school-aged children and adolescents. Bull World Health Organ 2007; 85:660-7.

9. Hamill PV, Drizd TA, Johnson CL, Reed RB, Roche AF. NCHS growth curves for children birth18 years: United States. Vital Health Stat 11 1977; (165):i-iv, 1-74.

10. Cole TJ, Flegal KM, Nicholls D, Jackson AA. Body mass index cut offs to define thinness in children and adolescents: international survey. BMJ 2007; 335:194.

\section{Acknowledgments}

This work was supported by the Brazilian Council for Scientific and Technological Development (CNPq: 471172/2001-4, 475122/2003-8, 301076/1989-8, 311801/2006-4, 302992/2003-0) and the Oswaldo Cruz Foundation (Programa Estratégico de Apoio à Pesquisa em Saúde - PAPES: 250139).
11. Instituto Brasileiro de Geografia e Estatística. Censo demográfico 2000: agregados por setores censitários dos resultados do universo. $2^{\text {a }}$ Ed. Rio de Janeiro: Instituto Brasileiro de Geografia e Estatística; 2003.

12. Haldane JBS. On the method of estimating frequencies. Biometrika 1945; 33:222-5.

13. Vasconcellos MTLS, Silva PLN, Szwarcwald CL. Sampling design for the World Health Survey in Brazil. Cad Saúde Pública 2005; 21 Suppl 1:S89-99.

14. Bossan FM, Anjos LA, Vasconcellos MTL, Wahrlich V. Nutritional status of the adult population in Niterói, Rio de Janeiro, Brazil: the Nutrition, Physical Activity, and Health Survey. Cad Saúde Pública 2007; 23:1867-76.

15. Silva PLN. Calibration estimation: when and why, how much and how. Rio de Janeiro: Instituto de Brasileiro de Geografia e Estatística; 2004. (Textos para Discussão da Diretoria de Pesquisas, 15).

16. Must A, Dallal GE, Dietz WH. Reference data for obesity: 85 th and 95 th percentiles of body mass index (wt/ht 2 ) and triceps skinfold thickness. Am J Clin Nutr 1991; 53:839-46.

17. Särndal CE, Swensson B, Wretman JH. Model assisted survey sampling. New York: Springer-Verlag; 1992.

18. Malina RM, Katzmarzyk PT. Validity of the body mass index as an indicator of the risk and presence of overweight in adolescents. Am J Clin Nutr 1999; 70:131S-6S.

19. Cacciari E, Milani S, Balsamo A, Dammacco F, De Luca F, Chiarelli F, et al. Italian cross-sectional growth charts for height, weight and BMI (6-20 y). Eur J Clin Nutr 2002; 56:171-80.

20. Conde WL, Monteiro CA. Body mass index cutoff points for evaluation of nutritional status in Brazilian children and adolescents. J Pediatr (Rio J.) 2006; 82:266-72.

21. Fredriks AM, van Buuren S, Jeurissen SE, Dekker FW, Verloove-Vanhorick SP, Wit JM. Height, weight, body mass index and pubertal development references for children of Moroccan origin in the Netherlands. Acta Paediatr 2004; 93:817-24. 
22. Inokuchi M, Matsuo N, Anzo M, Hasegawa T. Body mass index reference values (mean and SD) for Japanese children. Acta Paediatr 2007; 96:1674-6.

23. Ozer BK. Growth reference centiles and secular changes in Turkish children and adolescents. Econ Hum Biol 2007; 5:280-301.

24. Razzaghy Azar M, Moghimi A, Montazer M, Sadeghi HM, Golnari P, Sadigh N, et al. Cross-sectional reference values for height, weight and body mass index of school children living in Tehran, Iran. Ann Hum Biol 2006; 33:471-9.

25. Vieira MFA, Araújo CLP, Neutzling MB, Hallal PC, Menezes AMB. Diagnosis of overweight and obesity in adolescents from the 1993 Pelotas Birth Cohort Study, Rio Grande do Sul State, Brazil: comparison of two diagnostic criteria. Cad Saúde Pública 2007; 23:2993-9.

26. Chiara V, Sichieri R, Martins PD. Sensibilidade e especificidade de classificação de sobrepeso em adolescentes, Rio de Janeiro. Rev Saúde Pública 2003; 37:226-31.

27. von Der Heyde MED, Amorim STSP, Lang RMF, von Der Heyde R. Perfil nutricional de adolescentes da cidade de Curitiba, PR. In: Obesidade e Anemia Carencial na Adolescência: Simpósio. São Paulo: Instituto Danone; 2000. p. 227.

28. Jinabhai CC, Taylor M, Reddy P, Monyeki D, Kamabaran N, Omardien R, et al. Sex differences in under and over nutrition among school-going black teenagers in South Africa: an uneven nutrition trajectory. Trop Med Int Health 2007; 12:944-52.

29. Abalkhail B. Overweight and obesity among Saudi Arabian children and adolescents between 1994 and 2000. East Mediterr Health J 2002; 8:470-9.

30. Serra Majem L, Ribas Barba L, Aranceta Bartrina J, Pérez Rodrigo C, Saavedra Santana P, Peña Quintana L. Obesidad infantil y juvenil en España. Resultados del Estudio enKid (1998-2000). Med Clin 2003; 121:725-32.
31. Mei Z, Grummer-Strawn LM, Pietrobelli A, Goulding A, Goran MI, Dietz WH. Validity of body mass index compared with other body-composition screening indexes for the assessment of body fatness in children and adolescents. Am J Clin Nutr 2002; 75:978-85.

32. Dietz WH, Robinson TN. Use of the body mass index (BMI) as a measure of overweight in children and adolescents. J Pediatr 1998; 132:191-3.

33. Kotchen JM, Kotchen TA, Guthrie Jr. GP, Cottrill CM, McKean HE. Correlates of adolescent blood pressure at five-year follow-up. Hypertension 1980; 2 (4 Pt 2):124-9.

34. Gidding SS, Bao W, Srinivasan SR, Berenson GW. Effects of secular trends in obesity on coronary risk factors in children: the Bogalusa Heart Study. J Pediatr 1995; 127:868-74.

35. Must A, Jacques PF, Dallal GE, Bajema CJ, Dietz WH. Long-term morbidity and mortality of overweight adolescents: a follow-up of the Harvard Growth Study of 1922 to 1935. N Engl J Med 1992; 327:1350-5.

36. Sardinha LB, Going SB, Teixeira PJ, Lohman TG. Receiver operating characteristic analysis of body mass index, triceps skinfold thickness, and arm girth for obesity screening in children and adolescents. Am J Clin Nutr 1999; 70:1090-5.

37. Williams DP, Going SB, Lohman TM, Harsha DW, Srinivasan SR, Webber LS, et al. Body fatness and risk for elevated blood pressure, total cholesterol, and serum lipoprotein ratios in children and adolescents. Am J Public Health 1992; 82:358-63.

Submitted on $17 /$ Oct/2008

Final version resubmitted on 27/Mar/2009

Approved on 06/Apr/2009 